Acknowledgements: We gratefully acknowledge Prof. Uwe Haberkorn (University Hospital Heidelberg and DKFZ, Heidelberg, Germany) and iTheranostics Inc. (Dulles, VA, USA) for providing the precursor FAPI-04.

Disclosure of Interests: Christina Bergmann: None declared, Jörg H.W. Distler Speakers bureau: Actelion, Anamar, ARXX, Pharma, Boehringer Ingelheim, Celgene, Galapagos, GSK, Inventiva, JB Therapeutics, and UCB, Grant/research support from: Anamar, Active Biotech, Array Biopharma, ARXX, aTyr, BMS, Bayer Pharma, Boehringer Ingelheim, Celgene, Galapagos, GSK, Inventiva, Novartis, Sanofi-Aventis, RedX, UCB, Christoph Treutlein: None declared, Koray Tascilar Speakers bureau: Gilead sciences GmbH, Pfizer Turkey, UCB Turkey, Anna-Theresa Mueller: None declared, Armin Atzinger: None declared, Alexandru-Emil Matei: None declared, Johannes Knitza: None declared, Andrea-Hermina Györfi: None declared, Anja Lueck: None declared, Clara Dees: None declared, Alina Soare: None declared, Andreas Ramming: None declared, Verena Schönau: None declared, Oliver Distler Speakers bureau: Arxx Therapeutics, Baecon Discovery, Blade Therapeutics,Bayer, Böhringer Ingelheim, Catenion,Competitive Drug Development International Ltd, Corbuspharma, CSL Behring, ChemomAb, Horizon Pharmaceuticals, Ergonex, Galaapagos NV, Glenmark Pharmaceuticals,GSK, Inventiva, Italfarmaco, IQvia, Kymera, Lilly, Medac, Medscape, MSD, Novartis, Pfizer, Roche, Sanofi, Taget Bio Sciencec, UCB, Grant/research support from: Bayer,Böhringer Ingelheim, Mitsubishi Tanabe Pharma, Olaf Prante: None declared, Philipp Ritt: None declared, Theresa Ida Goetz: None declared, Markus Koehner: None declared, Michael Cordes: None declared, Tobias Baeuerle: None declared, Torsten Kuwert Speakers bureau: Honoraria for occasional lectures by Siemens Healthineers, Grant/research support from: Research grant to the Clinic of Nuclear Medicine by this entity covering projects in the field of SPECT/CT, Georg Schett: None declared, Christian Schmidkonz: None declared DOI: 10.1136/annrheumdis-2021-eular.114

\section{OP0273 \\ THE SCLERODERMA CLINICAL TRIALS CONSORTIUM DAMAGE INDEX (SCTC-DI) IN A SYSTEMIC SCLEROSIS COHORT WITH 10-YEARS FOLLOW-UP}

M. G. Lazzaroni ${ }^{1}$, M. Breda ${ }^{1}$, F. Franceschini ${ }^{1}$, P. Airò ${ }^{1} .{ }^{1}$ ASST Spedali Civili of Brescia, University of Brescia, Rheumatology and Clinical Immunology Unit, Department of Clinical and Experimental Sciences, Brescia, Italy

Background: Systemic Sclerosis (SSc) is characterized by increased mortality and organ damage accrual. A composite SSc Damage Index was recently developed by the Scleroderma Clinical Trials Consortium (SCTC-DI) and was demonstrated as a predictor of mortality both in the Australian derivation cohort and in the Canadian validation cohort.

Objectives: To evaluate in a single centre cohort of SSc patients with 10-years follow-up: (1) the evolution of organ damage over time; (2) factors associated with the development and accrual of organ damage.

Methods: A retrospective analysis was performed on patients prospectively followed in our centre from 1989 to 2019. Organ damage was evaluated with SCTC-DI (0-55 scale; moderate damage $>5$, severe damage $>12$ ) and comorbidities with Charlson Comorbidity Index $(\mathrm{CCl}$, which includes the age of the patient). Patients were included when a follow-up of at least 10 years was available together with SCTC-DI at the diagnosis (baseline, T0), 1 year (T1), 5 years (T5) and 10 years (T10) after the diagnosis. Univariable and multivariable analysis (logistic regression) were performed when appropriated.

Results: 253 SSc patients were included (female 93\%; Caucasians: 99\%; median age at diagnosis: 52 years (IQR: 43-60); diffuse cutaneous subset: 15\%; anti-centromere (ACA) + 55\%; anti-Topoisomerase 1+20\%; anti-RNA polymerase III+: $4 \%$; ever smokers: $28 \%$ ). Median interval between the first SSc symptom other than Raynaud's phenomenon and the diagnosis was 1 year. SCTC-DI progressively increased from diagnosis to T10 ( $p<0.0001$; Kruskal-Wallis test). Moderate damage (score:6-12) was observed in 22 patients at T0 (8.7\%), in 30 at T1 $(11.9 \%)$, in 45 at T5 $(17.7 \%)$ and in 73 at T10 (28.9\%). None of the patients had severe damage (score:13-55) at T0 and T1, while it was present in 6 at T5 (2.4\%) and in 13 at T10 (5.1\%).

At TO no difference in SCTC-DI scores was observed when comparing different subgroups according to gender (female vs. male), disease subsets (diffuse vs. limited) and autoantibodies (ACA- vs. ACA+). At T1, SCTC-DI score was higher in patients with diffuse vs. limited cutaneous subset, and ACA- vs ACA $+(p<0.0001$ for both).

Multivariable analysis demonstrated that a moderate or severe organ damage (SCTC-DI score $>5$ ) at 5 years was positively associated with diffuse cutaneous involvement (p:0.009, OR 4.55, 1.46-14.1), SCTC-DI at TO (p:0.015, OR 1.34, 1.06-1.70) and at T1 (p:<0.0001, OR 1.65, 1.30-2.07), and negatively associated with ACA+ (p:0.024, OR 0.32, 0.12-0.86), while CCl and male sex showed no association. At 10 years SCTC-DI $>5$ was associated with diffuse cutaneous involvement (p:0.013, OR 4.30, 1.36-13.7), SCTC-DI at T5 (p:<0.0001, OR 1.67, 1.38-2.01), while SCTC-DI at TO, CCI, male sex and ACA+ had no association. Among 253 patients, 90 (36\%) died after $>10$ years of follow-up. In non-survivors, as compared to survivors, SCTC-DI score was significantly higher at the baseline (T0) and during the entire follow-up ( $p<0.0001$ for every timepoint).
Conclusion: At the end of 10-years follow-up (T10), 35\% of patients in our cohort had moderate or severe organ damage (SCTC-DI score $>5$ ). Diffuse cutaneous involvement was associated with higher SCTC-DI scores at different time points (T5 and T10). Organ damage, quantified by SCTC-DI at different time points, was confirmed as a factor associated with mortality in patients who reached more than 10 years of follow-up.

REFERENCES:

[1] Ferdowsi N, et al. Ann Rheum Dis. 2019;78:807-16.

Disclosure of Interests: None declared

DOI: 10.1136/annrheumdis-2021-eular.582

\section{PARE Abstract session}

\section{OP0274-PARE EVALUATION OF PATIENT SATISFACTION FOR TELEHEALTH (PHONE AND VIDEO) IN RHEUMATOLOGY OUTPATIENTS DURING COVID-19 PANDEMIC}

Y. Oh ${ }^{1,2}$, A. Hennessey ${ }^{1,2}$, L. Young ${ }^{1,2}$, D. Yates ${ }^{1,2}$, C. Barrett ${ }^{1,2} .{ }^{1}$ Redcliffe Hospital, Rheumatology, Redcliffe, Australia; ${ }^{2}$ The University of Queensland, Medicine, Saint Lucia, Australia

Background: Telehealth via phone (TPhone) or video conference (TVideo) in rheumatology has been a topic of interest for many years. Its use was rapidly expanded due to the international public health emergency of coronavirus dis ease-19 (COVID-19) outbreak in 2020. Australian Medicare Benefits Schedule (MBS) swiftly enabled temporary MBS telehealth items on 13 March 2020, currently extended until 31 March $2021^{1}$. In the early phase of the COVID-19 pandemic, Antony et al. conducted a single-centre public survey to assess patient perception of rheumatology telehealth. Their results showed that $98.4 \%$ of patients consider telehealth acceptable during the pandemic ${ }^{2}$. It is unclear, however, whether this positive perception persists after patients experience a telehealth. In addition, a survey data in 2019 suggested more than half of Australian rheumatologists work in private practice ${ }^{3}$. Therefore, inclusion of private patients will better represent patient perception of telehealth.

Objectives: The aim of this study was to evaluate patient satisfaction with telehealth during the COVID-19 pandemic. This would determine its feasibility to be integrated in future rheumatology outpatient model.

Methods: A questionnaire containing 30 questions was sent to rheumatology patients who attended telehealth appointments at a level 2 public hospital and a local private clinic between April and May 2020. The questionnaires aimed to obtain information on baseline demographics (sex, age, public or private patient, employment status, visual or auditory impairment), appointment details (TPhone or TVideo, usual arrangement for face-to-face (F2F) appointment, cost effectiveness) and appointment satisfaction using a 5-point Likert scale. Descriptive statistical analysis was conducted.

Results: The questionnaire was sent to 1452 patients, of which 494 patients responded (34\%). Female predominance $(77.1 \%)$ and a higher proportion of TPhone $(79.1 \%)$ was seen in the respondents. A majority of patients were existing patients known to the services $(90.9 \%)$. More than $70 \%$ of responses indicated overall satisfaction in specialist care via telehealth, and $88.7 \%$ perceived this suitable during a pandemic. Of all respondents, $21.7 \%$ were prescribed new medication, and the majority of these patients were confident in taking the new medication after the telehealth appointment. Future acceptability for TPhone was significantly lower in private patients compared to public patients $(p=0.01)$. Subgroup analysis revealed that higher telehealth satisfaction was associated with needing to take time off work to attend face-to-face appointment $(p=0.02)$, perception of cost effectiveness $(p<0.001)$ and TVideo $(p=0.03)$.

Conclusion: This is the first study which included both public and private rheumatology patients to evaluate patient satisfaction for telehealth during the COVID-19 pandemic. Overall high level of satisfaction was seen in telehealth most notably associated with its cost effectiveness. A higher percentage of patients who had TVideo compared to TPhone were receptive to future telehealth via TVideo, supportive of the importance of visual cues. This in turn will have significant administrative and technological burdens to coordinate in comparison to a F2F or TPhone review. This qualitative study provides valuable insight of patient perception of telehealth, which has the potential to compliment the traditional rheumatology outpatient model of care following the pandemic.

REFERENCES:

[1] COVID-19 Temporary MBS Telehealth Services 2020 [Available from: http://www.mbsonline.gov.au/internet/mbsonline/publishing.nsf/Content/ Factsheet-TempBB

[2] Antony A, Connelly K, De Silva T, Eades L, Tillett W, Ayoub S, et al. Perspec tives of Patients With Rheumatic Diseases in the Early Phase of COVID-19. Arthritis Care \& Research. 2020;72(9):1189-95.

[3] Association AR. Workforce Survey Exective Summary 20192019 [Available from: https://rheumatology.org.au/members/documents/WorkforceSurveyExecutiveSummary-websiteMay2019.pdf. 